interpretation that CDIb and CD1b-like molecules were deleted during murine evolution. The conclusion that CDlb-like molecules are not a recent innovation is significant as it suggests that cell-mediated immunity directed at non-peptide antigens may have occurred early in the development of the immune system, perhaps even preceding the recognition of peptide antigens by the polymorphic, classical MHC class I and II molecules.

\section{Steven Balk}

Division of Hematology-Oncology,

Beth Israel Hospital,

Boston,

Massachusetts 02215, USA

1. Parham, P. Nature 372, 615 (1994).

2. Beckman, E.M. et al Nature 372, 691-694 (1994)

3. Wang, C.R. et al. Molec. Immun. 25, 945-952 (1988).

4. Calabi, F. et al. Immunogenetics 30, 370-377 (1989).

5. Bujdoso, R. et al. J. exp. Med. 170, 1285-1318 (1989).

6. Moseley, W.S., Watson, M.L., Kingsmore, S.F. \& Seldin, M.F. Immunogenetics 30, 378-382 (1989).

\section{'Functional' haplodiploidy}

SIR - The coffee berry borer (Hypothenemus hampei) is the main insect pest of coffee worldwide. The recent evolution and rapid spread of high levels of resistance to endosulfan (a cyclodiene-type insecticide) in the South Pacific island of New Caledonia therefore constitutes a major threat to the international coffee industry ${ }^{1}$. Like many other members of the scolytid bark beetle, this species shows a highly female-biased sex ratio and incestuous inbreeding ${ }^{2}$; thus, a single mated female enters the coffee berry and the numerous female progeny are obliged to mate with their few dwarf and flightless male sibs. In some bark beetle species this type of life history (inbreeding polygyny and spanandry) is associated with haplodiploidy ${ }^{2}$.

We have previously shown that cyclodiene resistance in $H$. hampei is associated with a single point mutation in the GABA ( $\gamma$-aminobutyric acid) receptor subunit gene Resistance to dieldrin, or $R d l$, and that this same mutation is present in several strains from New Caledonia ${ }^{3}$. Previous insecticide bioassays have also shown that resistance is apparently sex-linked ${ }^{4}$. Thus, consistent with true haplodiploid inheritance, paternally derived resistance is not expressed in males or transmitted through males to progeny.

To test this possibility, we used two PCR-based diagnostic tests, polymerase chain reaction amplification of specific alleles (PASA) ${ }^{3}$ and single-stranded conformational polymorphism analysis $(\mathrm{SSCP})^{5}$, to determine the genotype of the progeny of reciprocal crosses of $F_{1}$ males and females of known parentage. Interestingly, PASA with either the resistant or susceptible specific PCR primer (PASA-R or PASA-S) shows that both resistant and

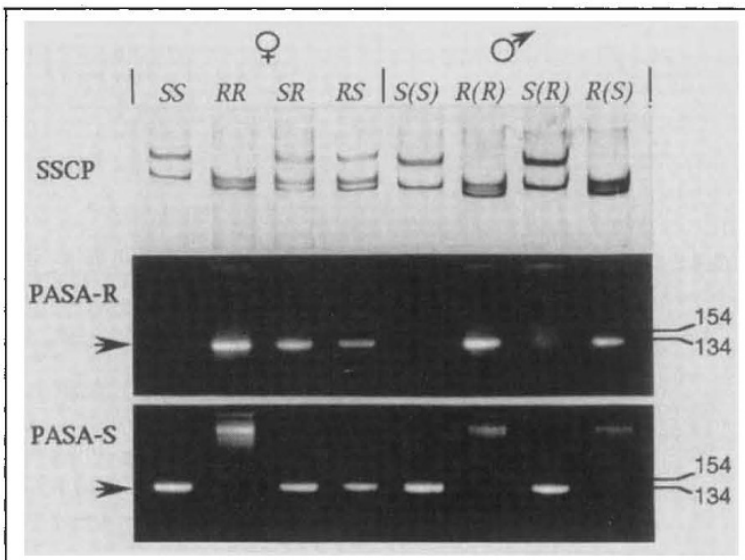

FIG. 1 SSCP and PASA analysis of males and females homozygous susceptible $S S$, homozygous resistant $R R$ or heterozygous $R S$ for resistance. Note that in females both maternal and paternal alleles (in parentheses) can be detected by either technique, whereas in male progeny both techniques fail to amplify paternally derived alleles. Thus, banding patterns associated with the predicted genotypes $S(S)$ and $S(R)$ are identical, as are the patterns for $R(R)$ and $R(S)$.

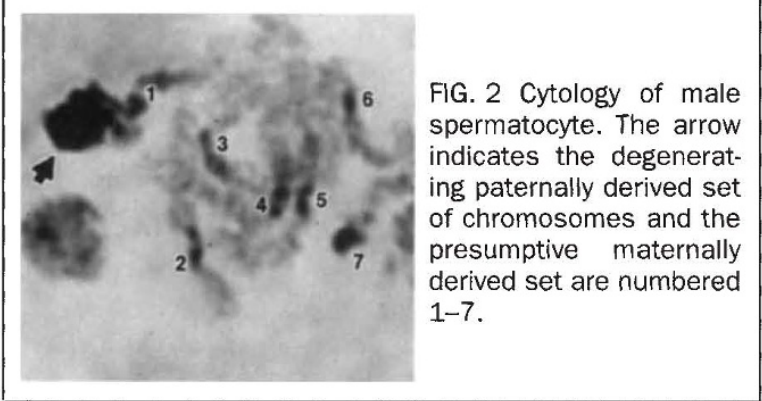

susceptible alleles fail to amplify in males when paternally derived. These data are confirmed by the simultaneous use of SSCP on the same amplification products: SSCP banding patterns for the $S(S)$ and $S(R)$, and the $R(R)$ and $R(S)$ each show the same pattern, because the paternally derived alleles (in parentheses) are not amplified in males (Fig. 1). This again appears consistent with haplodiploidy, in which males would be haploid and females diploid.

Cytological examination, however, reveals that although somatic tissues of females are $2 n=14$ as previously report$\mathrm{ed}^{6}$, in the male soma one of the sets of chromosomes (presumably the paternal

\footnotetext{
1. Brun, L. O., Marcillaud, C., Gaudichon, V. \& Suckling, D. M. J. econ. Ent. 82, 1311-1316 (1989).

2. Kirkendall, L. R. in Evolution and Diversity of Sex Ratio in Insects and Mites (eds Wrensch, D. L. \& Ebbert, M. A.) 235-345 (Chapman \& Hall, New York, 1993).

3. ffrench-Constant, R. H., Steichen, J. C. \& Brun, L. O. Bull. ent. Res. 84, 11-16 (1994).

4. Brun, L. O. et al. J. econ. Ent. (in the press)

5. Coustau, C. \& ffrench-Constant, R. H. Pestic. Sci. (in the press).

6. Bergamin, J. \& Kerr, W. E. Cienc. Cult. 3, 117-121 (1951).

7. Bull, J. J. in Evolution of Sex Determining Mechanisms 145-191 (Benjamin/Cummings, Menlo Park, California, 1983).

8. Brun, L. O., Marcillaud, C., Gaudichon, V. \& Suckling, D. M. Buil. ent. Res. 80, 129-135 (1990).

9. Brun, L. O. \& Suckling, D. M. J. econ. Ent. 85, 325-334 (1992).
}

set) is compacted into a darkly staining ball of chromatin. Further, in meiosis during the first (only) meiotic division the paternally derived set begins to degenerate while the maternally derived set condenses and divides (Fig. 2). Therefore, males are actually diploid, but the paternal set of chromosomes is condensed in both the soma and germ line, and is lost during sperm production. The coffee berry borer is therefore 'functionally' haplodiploid, although males still actually possess two sets of chromosomes.

Similar mechanisms for the destruction of paternally inherited genetic material have been observed in other insects and mites ${ }^{7}$. However, we believe our findings represent the first demonstration of the inheritance of insecticide resistance via functional haplodiploidy. This leads to an interesting mode of inheritance of resistance whereby females are continuously backcrossed to their female grandparents and may therefore explain the observed rapid spread of resistance in New Caledonia ${ }^{8,9}$ : first, because recessive or semi-dominant resistance genes are exposed directly to selection in effectively hemizygous males; second, as there is no outbreeding, resistance will be perpetuated within individual, completely isolated, inbreeding lines; and third, within these lines, the continuous maternal backcrossing will promote the rate at which resistance genes achieve homozygosity. Thus, once a resistance-associated mutation has arisen it will be rapidly perpetuated within, and spread via, a single inbreeding line. Luc 0. Brun

\section{Philippe Borsa}

Veronique Gaudichon

Institut Français de Recherche Scientifique pour le Développement en Cooperation (ORSTOM),

Noumea, New Caledonia

Jeffrey J. Stuart

Department of Entomology,

Purdue University,

West Lafayette,

Indiana 47907, USA

Kate Aronstein

Christine Coustau

Richard H. ffrench-Constant

Department of Entomology,

University of Wisconsin,

Madison, Wisconsin 53706, USA 